\title{
Extracellular Vesicles and their miRNA Cargo: A Means of Communication between Soma and Germline in the Mammalian Reproductive System
}

\author{
Emmanuelle Maciel $^{\star a b}$ and Isabelle M. Mansuy ${ }^{a}$
}

\begin{abstract}
MicroRNAs (miRNAs) are small non-coding RNAs able to silence gene expression by RNA interference. They are present in cells but many are contained in extracellular vesicles (EVs) that can be released by cells in the circulation. Circulating EVs can encounter other cells in the body and deliver their miRNA cargo. This process enables long-range communication between different cells and has been proposed to play important physiological roles. One of these roles that remains less well studied is in the reproductive system. In ovaries and testes, constant communication between somatic cells and developing germ cells is necessary for their maturation and EVs have been proposed to contribute to this communication. EVs might also enable external factors derived from environmental exposure to reach gametes and keep a trace of exposure for the offspring.
\end{abstract}

Keywords: Extracellular vesicle $\cdot$ Gametes $\cdot$ Mammals $\cdot$ miRNA $\cdot$ Reproduction

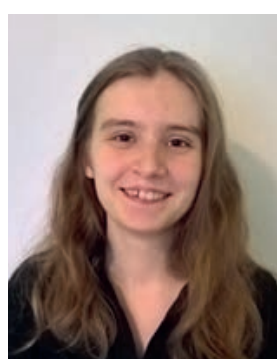

Emmanuelle Maciel is a master student at the Ecole Normale Supérieure de Lyon in France. She is currently working in the Laboratory of Neuroepigenetics of Isabelle Mansuy at the University and ETH Zurich for an internship.

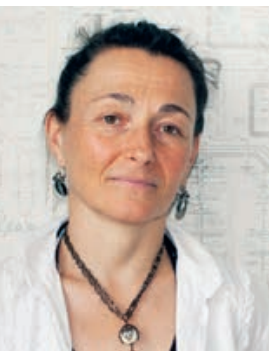

Isabelle Mansuy is Professor in Neuroepigenetics at the Medical Faculty of the University Zürich (UZH), and the Department of Health Science and Technology of the Swiss Federal Institute of Technology Zürich (ETHZ). Her lab is part of the Center for Neuroscience Zürich. She completed a $\mathrm{PhD}$ in Developmental Neurobiology at the Friedrich Miescher Institute in Basel, Switzerland and the Université Louis Pasteur Strasbourg, France, followed by postdoctoral training in the lab of Eric Kandel at the Center for Learning and Memory at Columbia University in New York. She was appointed Assistant Professor in Neurobiology at the ETHZ in Dec 1998, then Associate Professor in Molecular Cognition at UZH and ETHZ in 2005 and Full Professor in Neuroepigenetics in 2013.

\section{Introduction}

MicroRNAs (miRNAs) are a type of small non-coding RNAs that can silence the expression of genes by RNA interference. They are involved in the regulation of many biological processes including cell differentiation, proliferation and apoptosis during development and adulthood. Many miRNAs are phylogenetically conserved.[1] Their biogenesis starts with the transcription of a primary double-stranded miRNA (pri-miRNA) by RNA polymerase II or III, ${ }^{[2]}$ which adopts a hairpin secondary structure. PrimiRNAs are then cleaved in pre-miRNAs by the RNase Drosha, ${ }^{[2]}$ which acts in a microprocessor complex. ${ }^{[3]}$ Pre-miRNAs are then exported outside the nucleus by Exportin-5 ${ }^{[4]}$ and further processed in the cytoplasm by Dicer, ${ }^{[5]}$ which cleaves the hairpin enabling the two strands to dissociate. Mature miRNAs can regulate gene expression ${ }^{[6]}$ by interfering with target messenger RNAs (mRNA) in two ways. If they are in a minority compared to their target mRNAs, they associate with RISC (RNA-induced silencing complex) through proteins of the Argonaute family such as AGO2 that recognise miRNAs, then bind to the mRNAs. ${ }^{[7]}$ RISC cleaves the mRNAs and the resulting fragments can themselves become interfering RNAs, thereby amplifying silencing. ${ }^{[8]}$ It was shown in plants that if miRNAs are abundant compared to the target mRNAs, they associate with proteins of the RITS (RNA-induced transcriptional silencing) complex, then bind to the mRNAs for silencing[7] (Fig. 1).

In mammals, miRNAs can be secreted by cells and circulate either freely ${ }^{[9]}$ in HDL or LDL, ${ }^{[10]}$ or in extracellular vesicles (EVs). [11] EVs and their miRNAs cargo play major roles in different biological processes such as proliferation, apoptosis and angiogenesis, ${ }^{[12]}$ and have been associated with diseases such as cancers and nervous system pathologies. [10]

MiRNAs also fulfil important functions in reproduction, in particular in the maturation of gametes. In females, oocytes are associated with follicular somatic cells and mature collectively in the ovary, ${ }^{[13]}$ while in males, sperm cells mature in the epididymis where they acquire motility and the ability to fertilise an egg. ${ }^{[12]}$ These steps of final maturation rely on the local microenvironment and involve EVs and their miRNA cargo. ${ }^{[14]}$ These miRNAs 


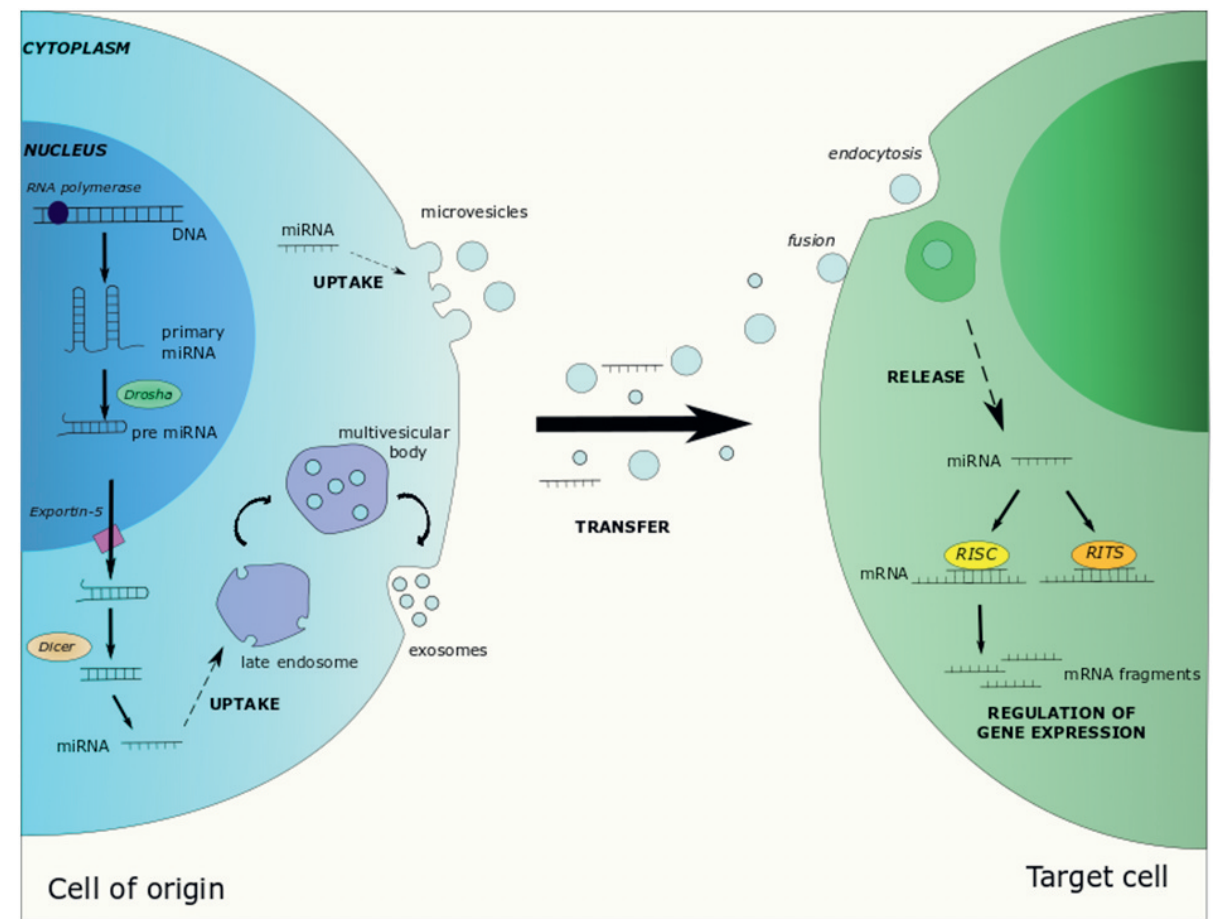

Fig. 1. Biogenesis of miRNAs and transfer from the cell of origin to the target cell.

are important for reproductive functions themselves but are also thought to be carriers of parental information reflecting past experiences and environmental exposure. Since miRNAs can be modified by factors like diet, stress, endocrine disruptor exposure, etc., their presence in gametes may be a way to keep traces of parental exposure. Today, miRNAs in EVs of the reproductive tract are considered as potential vectors of information transfer from parent to offspring.

\section{Intercellular Communication via miRNAs Transported in EVs}

\subsection{Diversity of EVs}

EVs are very diverse and can be produced by and targeted to various cell types and contribute to multiple biological processes. Initially thought to be involved in the elimination of cell debris, they are now considered as major physiological regulators of biological functions in health and disease. ${ }^{[15]}$ EVs can be isolated, quantified and classified into subtypes but the procedures are difficult and often not specific. ${ }^{[16]}$ No marker has been identified to establish an efficient classification ${ }^{[17]}$ but vesicles can be distinguished by size. Exosomes are traditionally vesicles of 30 and $150 \mathrm{~nm}$ diameter and microvesicles between $50 \mathrm{~nm}$ to $1 \mu \mathrm{m} .{ }^{[18,19]}$ Size is, however, not an ideal parameter to distinguish vesicles because some exosomes and microvesicles overlap in size. ${ }^{[17]} \mathrm{EVs}$ can also be sorted depending on their biogenesis. Exosomes derive from maturing late endosomes, whose membrane buds inwardly to form multivesicular bodies. This invagination can be mediated by the protein complex ESCRT (Endosomal Sorting Complexes Required for Transport) ${ }^{[20-22]}$ or rely on the presence of sphingolipid ceramides. ${ }^{[23,24]}$ Multivesicular bodies are then targeted to the plasma membrane and release the vesicles they contain out of the cell by fusion. ${ }^{[25]}$ Microvesicles arise from budding of the plasma membrane itself, which can involve a redistribution of phospholipids ${ }^{[26]}$ and contraction of the acto-myosin network. ${ }^{[27]}$ The generic term of EVs will be used in this review.

Upon secretion, EVs are transferred into the extracellular matrix or the bloodstream, through which they can reach other cells. They are recognized by cells through protein-protein interactions involving for example membrane proteins such as tetraspanins ${ }^{[28]}$ and integrins, ${ }^{[29]}$ or heparin sulphate proteoglycans. ${ }^{[30]}$ EVs are then internalised by target cells through endocytosis, ${ }^{[29]}$ or fusion with the plasma membrane as is the case in low $\mathrm{pH}$ conditions in tumours. ${ }^{[31]} \mathrm{EV}$ content varies highly depending on cell type, mode of production and physiological conditions. They can contain proteins involved in the production of vesicles, transcription factors, ${ }^{[32,33]}$ proteins involved in gap junctions like connexins, etc. ${ }^{[34]}$ They also contain lipids that come from their cell of origin, some of which are required for internalisation by the target cell, for instance, phosphatidylserine on the outer part of the lipid bilayer. ${ }^{[35]}$ EVs are also rich in nucleic acids including mRNAs, long and small non-coding RNAs such as miRNAs, circRNAs (circular RNAs) and tRNAs (transfer RNAs), and tRNAs fragments (tRFs) ${ }^{[36,37]}$ and can sometimes contain DNA. ${ }^{[38]}$

\section{2 miRNA Sorting into EVs}

miRNAs are not randomly packed into EVs but are actively sorted. ${ }^{[39]}$ While some miRNAs are found essentially in cells, others are found in EVs, and are called EXOmiRNAs. ${ }^{\left[{ }^{[6]} \text { MiRNA }\right.}$ sorting in EVs inside the cell of origin operates via three main mechanisms.

Recognition of short sequences found on EXOmiRNAs: the EXOmotifs. Two of the most common EXOmotifs are GGAG located in 3' of the miRNA and C/UCCU/G located anywhere in the miRNA. ${ }^{[40]}$ EXOmotifs are recognised by ribonucleoproteins such as hnRNP A2B1 (heterogeneous ribonucleoprotein A2B1), a factor that exists as a cellular and exosomal form. The exosomal form is larger because it contains an additional SUMO residue necessary for EXOmiRNA sorting, thought to change hnRNP A2B1 subcellular localisation. ${ }^{[40]}$ Another ribonucleoprotein, Syncrip/hnRNP Q (synaptotagmin-binding protein), exists in hepatocytes and contributes to miRNA packaging into EVs. Its knock-down alters the packaging. ${ }^{[1]}$ Syncrip contains three RRM (RNA recognition motif) and a non-canonical N-terminal RNA-binding domain that has high sequence specificity. The $\mathrm{N}$-terminal domain recognises the EXOmotif GGCU/A of miRNAs and the affinity of the interaction is increased by cooperation with the canonical RRM. This cooperation enables Syncrip to recognise EXOmiRNAs with different 5 ' seed sequences. ${ }^{[42]}$ 
Recognition of a posttranslational modification on miRNAs. miRNAs with a 3' adenylation are found preferentially in cells, whereas miRNAs with a 3 ' uridylation tend to be found in EVs, ${ }^{[43]}$ suggesting that $3^{\prime}$ uridylation may be a sorting mechanism.

Recognition by a RISC protein. In human liver stem-like cells, AGO2 was shown to have a role in miRNA sorting by cooperating with Alix, a protein of the ESCRT machinery. ${ }^{[39]}$ Coimmunoprecipitation analyses showed that Alix bound to both AGO2 and miRNAs, and its knock-down significantly reduces miRNA in EVs. ${ }^{[44]}$

Connexins may allow the formation of gap junctions between exosomes and their target cells, thus enabling EVs to release their content into the cytoplasm. ${ }^{[45]}$ Once taken-up by the target cell, miRNA may act inside the cell to alter gene expression. For example, it was shown recently that exosomes secreted from adipose tissue deliver miRNA that regulate gene expression in a distant tissue such as the liver.[46] Thus, EVs and their RNA content are a means of cell-to-cell communication used in several biological contexts.

\section{Role of EV-mediated Communication in the Male Reproductive System}

Spermatogenesis is a complex process of production and maturation of reproductive cells that occurs in testes. Once produced in the seminiferous tubules, sperm cells are released in the epididymis, a long and narrow coiled tube (about 6 meters in humans), where they circulate and continue to mature. The epididymis is divided into three parts, the head (caput) where sperm enters, the body (corpus) through which sperm progresses and the tail (cauda), where it is stored until ejaculation. The maturation of sperm cells, which takes place in the epididymis and ends in the female genital tract with capacitation, confers motility and the capacity to fertilise the oocyte. ${ }^{[12]}$ Because the sperm genome is highly condensed, essentially by replacement of most histones by protamines, it is transcriptionally silent. Thus, its maturation is traditionally thought to not require transcription, although many transcripts are found in spermatozoa. ${ }^{[47]}$ Sperm maturation is thought to be controlled by interactions between sperm cells and their microenvironment including epithelial cells in the epididymal lumen and the female genital tract during ca- pacitation. ${ }^{[48]}$ This cell-to-cell communication involves EVs, in particular epididymosomes.

\subsection{Characteristics and Content of Epididymosomes}

Epididymosomes are produced by apocrine secretion from the apical part of epithelial cells of the epididymis that releases a bleb containing vesicles. The released bleb then disintegrates in the lumen of the epididymis and releases its content ${ }^{[49]}$ (Fig. 2). The released vesicles are a heterogeneous population of epididymosomes of two main types, CD9+ or CD9-. ${ }^{[12]}$ CD9+ epididymosomes are the smallest and range from 10 to $100 \mathrm{~nm}$. They bind to live spermatozoa and are thought to be involved in the acquisition of motility and egg recognition. CD9- epididymosomes rather have an affinity for dead spermatozoa. They contain proteins involved in ROS scavenging such as ELSPBP1 (EpididymaL SPerm Binding Protein 1), and help protect live sperm cells from factors released by dead spermatozoa. ${ }^{50]}$

Epididymosomes contain over 350 unique miRNAs ${ }^{[12]}$ and their miRNA composition varies along the epididymis. A comparison of epididymosomes from caput and cauda in bovine epididymis showed that, although vesicles have a comparable structure in both parts of the epididymis, the amount of small RNAs they contain is threefold higher in caput than cauda. But at the same time, while some miRNAs are enriched in caput, others are enriched in cauda, indicating that there are different populations of miRNAs across the different regions of the epididymis. Further, the miRNA content of epididymosomes in one region of the epididymis is different from that of epididymal epithelial cells of that region, suggesting that miRNAs are regulated differently in epididymosomes and epididymal cells. The shift in epididymosomal miRNA content across the epididymis suggests a changing microenvironment for each step of sperm maturation. ${ }^{[51]}$ Indeed, co-incubation of epididymosomes enriched in specific miRNAs and sperm cells was recently shown to result in the enrichment of sperm cells in these miRNAs, ${ }^{[12]}$ suggesting that miRNA can be transferred between epididymosomes and sperm cells.

MiRNAs transferred to maturing sperm cells through epididymosomes have important roles for reproductive functions and for
A

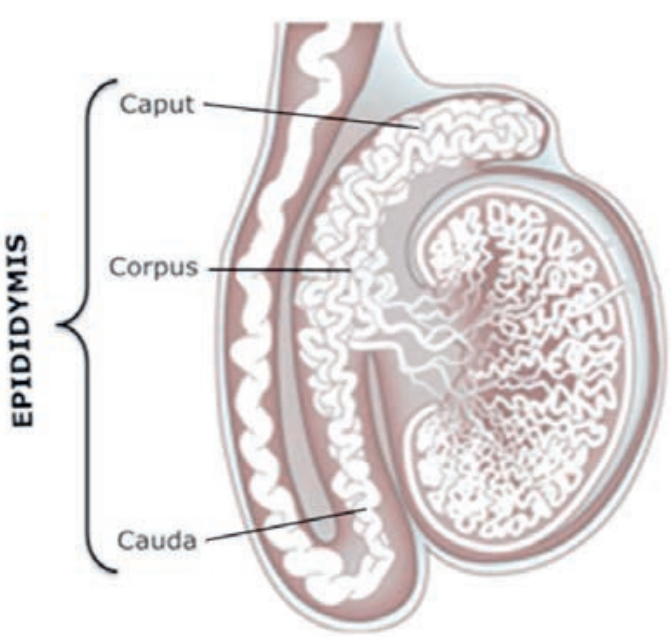

B

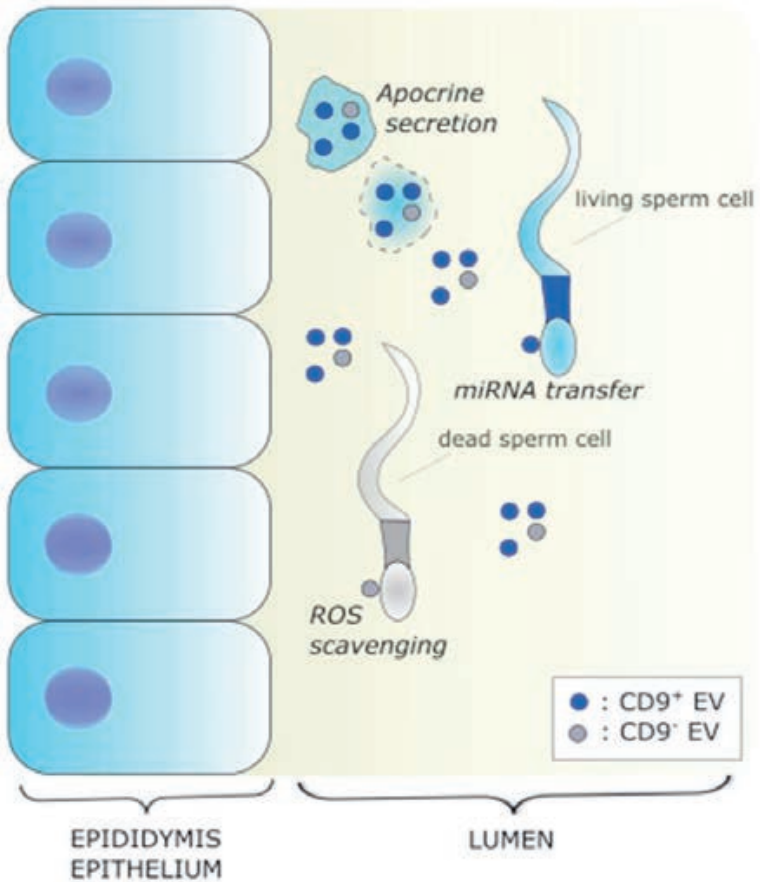

Fig. 2. EV mediated communication between sperm cells and the epididymis. A. Schematic representation of the testis and the epididymis. B. Transfer of CD9+ and CD9- EVs to living and dead sperm cells. miRNAs are transferred from CD9+ vesicles to sperm cells, thus enabling soma-germline communication. 
the future embryo. Sperm cells from caput or cauda epididymis have a different capacity to fertilise oocytes. Embryos generated from caput sperm have defects during implantation and post-implantation development, which can be rescued by adding miRNAs from cauda sperm, suggesting that miRNAs gained during transit in the epididymis are necessary for normal embryonic development.[52]

\subsection{Role of the Transfer of EVs miRNAs between Somatic Cells and Spermatozoa in Epigenetic Inheritance}

Epididymosomal miRNAs have also been suggested to play a role in the transfer of parental information to the offspring and contribute to a form of epigenetic inheritance. Recent studies have shown that the sperm RNA can be modified by exposure to environmental factors such as smoking ${ }^{[53]}$ or chronic traumatic stress. ${ }^{[54,55]}$ When total sperm RNA is injected into fertilized control oocytes (zygotes), behavioural and metabolic symptoms are reproduced in the resulting offspring as well as the grand offspring. ${ }^{[55]}$ A later study using a similar injection method suggested that 9 miRNAs found to be altered by paternal stress can induce a more rapid drop in corticosterone after an acute stress and showed a causal link between miRNA alteration in the sperm and phenotype of the offspring. ${ }^{[56]}$ However, no link has been established between epididymosomes, miRNA and sperm epigenome modifications in these studies.

A study in 2014 suggested that EVs mRNA, miRNA and proteins enable the transfer of information between soma and germline based on bioinformatic analyses. ${ }^{[57]}$ This was recently supported by another study showing that under chronic heavy alcohol exposure, the sperm content in small RNAs (including miRNAs) is altered, and that one type of small RNAs (tDR: RNA derived from tRNAs) is altered the same way in sperm and in epididymosomes. This suggests that epididymosomes might play a role in the communication of RNA changes between soma and sperm cells, ${ }^{[58]}$ possibly through long distances, but this needs to be further investigated. ${ }^{[57]}$

\section{Role of EV-mediated Communication in the Female Reproductive System}

In the female reproductive system, miRNAs can also be exchanged between cells through EVs circulating in body fluids. Like in males, this transfer enables the communication of factors which have a key role for reproduction and may play a role in the inheritance of environmentally acquired traits.

\subsection{Soma-Germline Communication in Follicular Maturation}

Primary oocytes are formed during embryonic life. They are surrounded by pre-granulosa cells, which are ovarian somatic cells and these form the primordial follicle. Those oocytes are arrested at the prophase stage of the first division of meiosis. The rest of meiosis and the oocyte maturation occur during reproductive cycles, in parallel with the development of follicles. There is constant communication between germinal and somatic cells at every step of oocyte and follicle formation. ${ }^{[13]}$ Several primordial follicles are recruited and grow, only one or a few of which (depending on the species) will be ovulated, and become primary and then secondary follicles: the pre-granulosa cells change their shape and become granulosa cells, the oocyte grows and the formation of zona pellucida begins, and the stromal cells turn into theca cells. At that stage, the oocyte and somatic cells of the follicle communicate, as they are physically linked by transzonal projections. ${ }^{[59]}$ The next step is the antral stage, where granulosa cells are separated into two groups: the mural granulosa cells on the wall of the follicle, and the cumulus cells around the oocyte; and where a cavity of fluid forms inside the follicle. ${ }^{[60]}$ This follicular fluid constitutes a microenvironment through which growth factors, chemokines and cytokines ${ }^{[61]}$ as well as EVs ${ }^{[62]}$ are communicated to the oocyte, which seems critical for the quality of the oocyte and its ability to be fertilized. ${ }^{[61]}$ After this, there is a surge of the hormone LH (luteinizing hormone), which triggers the resumption of meiosis and one or several oocytes are ovulated.[59]

\subsection{Importance of the Transfer of EV miRNAs between Soma and Oocytes for the Female Reproductive System}

Follicular fluid contains EVs carrying miRNA, which could play a role in follicular maturation. ${ }^{[63]}$ They probably target signalling pathways involved in oocyte growth, ${ }^{62]}$ follicular maturation, meiosis resumption and ovulation. ${ }^{[64]}$ Indeed, bioinformatics studies in humans identified the presence of a cluster of miRNAs carried by exosomes and enriched in follicular fluid compared to plasma, which could be involved in pathways such as WNT, TGFbeta, MAPK and ErbB. Two miRNAs involved in the regulation of DNA (cytosine-5-)-methyltransferase 3 alpha (DNMT3A) and DNA (cytosine-5-)-methyltransferase 3 beta (DNMT3B) were also identified, suggesting a role of EVs miRNAs in the regulation of DNA methylation in the oocyte. ${ }^{[64]}$

MiRNAs carried by EVs are involved in further stages of female reproduction. After ovulation, the oocyte can be fertilised by a mature sperm cell, which also involves cell-to-cell communication through EVs. Before being able to fertilise an oocyte, sperm cells need to complete their maturation. This phenomenon, known as capacitation, involves miRNAs delivered by oviductosomes (EVs secreted by the oviducts). ${ }^{[65]}$ After fertilisation, EV miRNAs are involved in the protection of the embryo against viral infections ${ }^{[66]}$ and in the cross talk between embryo and endometrium during embryo implantation. ${ }^{[67]}$ Taken together, these elements show the key role that EV miRNAs play in female reproduction.

\subsection{Transfer of RNA to the Offspring during Breast Feeding?}

Milk was shown to contain miRNAs, ${ }^{[68]}$ most of which are transported in EVs secreted by mammary epithelial cells or derived from milk fat globules. ${ }^{[69]}$ This might enable females to transfer information to their offspring during breast feeding. For this, EV miRNAs should resist digestion in the gastrointestinal tract of the pup, be taken-up by intestinal cells and subsequently by other organs, and then regulate gene expression in those tissues. Their ability to meet these three requirements is still debated.

A study in 2015 showed that milk miRNAs are degraded during digestion in mice, even if the fact that they are encapsulated in exosomes confers them a certain resistance. ${ }^{[70]} \mathrm{A}$ model of mice KO for two miRNAs abundant in milk (miR-375 and miR-200c/141) was used to assess the miRNA uptake by the intestine, liver and blood of pups fed with wild type milk. Very low miR-375 and miR-200c levels were observed in the tissues and blood, which suggests that there is no uptake of dietary miRNAs. However, several reports ${ }^{[71,72]}$ contradicted this study. For example, a study in 2017 showed that after in vitro human digestion, exosomes and their miRNA content were not significantly altered. ${ }^{72]}$ They are then taken-up by macrophages and intestinal epithelial cells of the offspring, ${ }^{[73]}$ where they seem to be able to regulate gene expression. ${ }^{[74]}$ Whether or not EV miRNAs transferred through breast milk indeed contribute to communicate information from the mother to her newborn requires additional research.

\section{Conclusion}

In both male and female reproductive systems, EVs play an important role in the communication between somatic cells and 
the germline. They carry small RNAs, such as miRNAs, that can contribute at two levels. First, EV miRNAs enable the proper functioning of the reproductive system itself. For example, miRNAs carried by epididymosomes are essential for proper maturation of sperm cells, which leads to an efficient implantation of the embryo after fertilisation and a proper post-implantation development. ${ }^{[52]}$ EV miRNAs are also important for oocyte maturation and play other roles in pregnancy. Second, some miRNAs can transfer factors that are acquired by the parents upon environmental exposure across their life. These factors can be transferred during the maturation of gametes and/or breast feeding. This way of transferring information to the offspring based on a horizontal mode of communication between somatic and germ cells during their last phases of maturation is not classical. It suggests that environmental cues can rapidly leave traces on gametes, which are thus potentially transferred to the immediate offspring, allowing for a mode of intergenerational epigenetic inheritance. The possibility that EVs may convey information from distant organs to the germline ${ }^{[57]}$ opens exciting and promising new avenues for the field of EVs.

EVs are widely used in clinical research and they have various therapeutic applications: they can be used in regenerative medicine, ${ }^{[75,76]}$ as a vehicle for drug delivery, ${ }^{[76,77]}$ and as diagnostic tools because they contain biomarkers that can indicate pathologies such as cancer. ${ }^{[76]}$ For these purposes, they can be isolated from patients in clinical laboratories, for example by ultrafiltration followed by size-exclusion liquid chromatography. ${ }^{[78]} \mathrm{EVs}$ are a promising therapeutic tool, too, yet many challenges still remain in this field. For example, the yield of the methods used to isolate them could be improved, as well as the quality and purity of the EVs obtained. ${ }^{[79]}$ Delivery of exosomes to the target organism also remains to be optimised, as a significant amount of EVs are taken up by macrophages instead of the target cell.[80]

\section{Acknowledgements}

I thank Dr Christine Miège for her help and advice concerning this review, and Alice Hugues and Marie Lebel for critical reading of the manuscript.

Received: February 28, 2019

[1] V. Ambros, Nature 2004, 431, 350, doi: 10.1038/nature02871.

[2] Y. Lee, C. Ahn, J. Han, H. Choi, J. Kim, J. Yim, J. Lee, P. Provost, O. Rådmark, S. Kim, V. N. Kim, Nature 2003, 425, 415, doi: 10.1038/nature01957.

[3] A. M. Denli, B. B. J. Tops, R. H. A. Plasterk, R. F. Ketting, G. J. Hannon, Nature 2004, 432, 231, doi: 10.1038/nature03049.

[4] E. Lund, S. Güttinger, A. Calado, J. E. Dahlberg, U. Kutay, Science 2004, 303, 95, doi: 10.1126/science. 1090599 .

[5] E. Lund, J. E. Dahlberg, Cold Spring Harb. Symp. Quant. Biol. 2006, 71, 59, doi: $10.1101 / \mathrm{sqb} .2006 .71 .050$.

[6] J. C. Carrington, V. Ambros, Science 2003, 301, 336, DOI: 10.1126/science. 1085242

[7] B. Khraiwesh, M. A. Arif, G. I. Seumel, S. Ossowski, D. Weigel, R. Reski, W. Frank, Cell 2010, 140, 111, doi: 10.1016/j.cell.2009.12.023.

[8] W. Filipowicz, S. N. Bhattacharyya, N. Sonenberg, Nature Rev. Genetics 2008, 9, 102, doi: $10.1038 / \mathrm{nrg} 2290$

[9] J. O'Brien, H. Hayder, Y. Zayed, C. Peng, Front. Endocrinol. 2018, 9, 402, doi: 10.3389/fendo.2018.00402.

[10] R. Bayraktar, K. Van Roosbroeck, G. A. Calin, Mol. Oncol. 2017, 11, 1673, doi: 10.1002/1878-0261.12144.

[11] H. Valadi, K. Ekström, A. Bossios, M. Sjöstrand, J. J. Lee, J. O. Lötvall, Nature Cell Biol. 2007, 9, 654, doi: 10.1038/ncb1596.

[12] J. N. Reilly, E. A. McLaughlin, S. J. Stanger, A. L. Anderson, K. Hutcheon, K. Church, B. P. Mihalas, S. Tyagi, J. E. Holt, A. L. Eamens, B. Nixon, Sci. Rep. 2016, 6, 31794, doi: 10.1038/srep31794.

[13] C. Di Pietro, J. Assist. Reprod. Genet. 2016, 33, 303, doi: 10.1007/s10815016-0657-9.

[14] J. C. da Silveira, A. C. F. C. M. de Ávila, H. L. Garrett, J. E. Bruemmer, Q. A. Winger, G. J. Bouma, J. Endocrinol. 2018, 236, R15, doi: 10.1530/JOE17-0200.

[15] C. Bang, T. Thum, Int. J. Biochem. Cell Biol. 2012, 44, 2060, doi: 10.1016/j. biocel.2012.08.007

[16] P. Li, M. Kaslan, S. H. Lee, J. Yao, Z. Gao, Theranostics 2017, 7, 789, doi: 10.7150/thno. 18133
[17] E. R. Abels, X. O. Breakefield, Cell. Mol. Neurobiol. 2016, 36, 301, doi: 10.1007/s 10571-016-0366-Z.

[18] B. T. Pan, K. Teng, C. Wu, M. Adam, R. M. Johnstone, J. Cell Biol. 1985, $101,942$.

[19] B. György, T. G. Szabó, M. Pásztói, Z. Pál, P. Misják, B. Aradi, V. László, É. Pállinger, E. Pap, Á. Kittel, G. Nagy, A. Falus, E. I. Buzás, Cell Mol. Life Sci. 2011, 68, 2667, doi: 10.1007/s00018-011-0689-3.

[20] M. Babst, D. J. Katzmann, E. J. Estepa-Sabal, T. Meerloo, S. D. Emr, Devel. Cell 2002, 3, 271, doi: 10.1016/S1534-5807(02)00220-4.

[21] D. J. Katzmann, M. Babst, S. D. Emr, Cell 2001, 106, 145, doi: 10.1016/ S0092-8674(01)00434-2

[22] M. Babst, D. J. Katzmann, W. B. Snyder, B. Wendland, S. D. Emr, Devel. Cell 2002, 3, 283, doi: 10.1016/S1534-5807(02)00219-8

[23] K. Trajkovic, C. Hsu, S. Chiantia, L. Rajendran, D. Wenzel, F. Wieland, P. Schwille, B. Brügger, M. Simons, Science 2008, 319, 1244, doi: 10.1126/ science. 1153124

[24] S. Stuffers, C. S. Wegner, H. Stenmark, A. Brech, Traffic 2009, 10, 925, doi: 10.1111/j.1600-0854.2009.00920.x.

[25] C. Harding, J. Heuser, P. Stahl, J. Cell Biol. 1983, 97, 329.

[26] P. Comfurius, J. M. G. Senden, R. H. J. Tilly, A. J. Schroit, E. M. Bevers, R. F. A. Zwaal, Biochim. Biophys. Acta Biomembr. 1990, 1026, 153, doi: 10.1016/0005-2736(90)90058-V.

[27] V. Muralidharan-Chari, J. Clancy, C. Plou, M. Romao, P. Chavrier, G. Raposo, C. D'Souza-Schorey, Curr. Biol. 2009, 19, 1875, doi: 10.1016/j. cub.2009.09.059

[28] S. Rana, S. Yue, D. Stadel, M. Zöller, Int. J. Biochem. Cell Biol. 2012, 44, 1574, doi: 10.1016/j.biocel.2012.06.018

[29] A. E. Morelli, A. T. Larregina, W. J. Shufesky, M. L. G. Sullivan, D. B. Stolz, G. D. Papworth, A. F. Zahorchak, A. J. Logar, Z. Wang, S. C. Watkins, L. D. Falo, A. W. Thomson, Blood 2004, 104, 3257, doi: 10.1182/ blood-2004-03-0824.

[30] H. C. Christianson, K. J. Svensson, T. H. van Kuppevelt, J.-P. Li, M. Belting, Proc. Natl. Acad. Sci. USA 2013, 110, 17380, doi: 10.1073/pnas. 1304266110.

[31] I. Parolini, C. Federici, C. Raggi, L. Lugini, S. Palleschi, A. De Milito, C. Coscia, E. Iessi, M. Logozzi, A. Molinari, M. Colone, M. Tatti, M. Sargiacomo, S. Fais, J. Biol. Chem. 2009, 284, 34211, doi: 10.1074/jbc. M109.041152.

[32] A.-C. Gradilla, E. González, I. Seijo, G. Andrés, M. Bischoff, L. GonzálezMendez, V. Sánchez, A. Callejo, C. Ibáñez, M. Guerra, J. R. Ortigão-Farias, J. D. Sutherland, M. González, R. Barrio, J. M. Falcón-Pérez, I. Guerrero, Nat. Commun. 2014, 5, 5649, doi: 10.1038/ncomms6649.

[33] J. C. Gross, V. Chaudhary, K. Bartscherer, M. Boutros, Nat. Cell Biol. 2012, 14, 1036, doi: $10.1038 / \mathrm{ncb} 2574$

[34] M. Varela-Eirin, A. Varela-Vazquez, M. Rodríguez-Candela Mateos, A. VilaSanjurjo, E. Fonseca, J. L. Mascareñas, M. Eugenio Vázquez, M. D. Mayan, Biochim. Biophys. Acta Mol. Cell Res. 2017, 1864, 728, doi: 10.1016/j. bbamcr.2017.02.001

[35] D. Fitzner, M. Schnaars, D. van Rossum, G. Krishnamoorthy, P. Dibaj, M Bakhti, T. Regen, U.-K. Hanisch, M. Simons, J. Cell Sci. 2011, 124, 447, doi: $10.1242 /$ jcs.074088.

[36] K. M. Kim, K. Abdelmohsen, M. Mustapic, D. Kapogiannis, M. Gorospe, Wiley Interdiscip. Rev. RNA 2017, 8, doi: 10.1002/wrna.1413.

[37] E. N. M. Nolte-'t Hoen, H. P. J. Buermans, M. Waasdorp, W. Stoorvogel, M. H. M. Wauben, P. A. C. 't Hoen, Nucleic Acids Res. 2012, 40, 9272, doi: 10.1093/nar/gks658

[38] L. Balaj, R. Lessard, L. Dai, Y.-J. Cho, S. L. Pomeroy, X. O. Breakefield, J. Skog, Nat. Commun. 2011, 2, 180, doi: 10.1038/ncomms1180.

[39] J. Guduric-Fuchs, A. O'Connor, B. Camp, C. L. O’Neill, R. J. Medina, D. A Simpson, BMC Genomics 2012, 13, 357, doi: 10.1186/1471-2164-13-357.

[40] C. Villarroya-Beltri, C. Gutiérrez-Vázquez, F. Sánchez-Cabo, D. PérezHernández, J. Vázquez, N. Martin-Cofreces, D. J. Martinez-Herrera, A Pascual-Montano, M. Mittelbrunn, F. Sánchez-Madrid, Nature Commun. 2013, 4, 2980, doi: 10.1038/ncomms3980.

[41] L. Santangelo, G. Giurato, C. Cicchini, C. Montaldo, C. Mancone, R. Tarallo, C. Battistelli, T. Alonzi, A. Weisz, M. Tripodi, Cell Rep. 2016, 17 , 799, doi: 10.1016/j.celrep.2016.09.031

[42] F. Hobor, A. Dallmann, N. J. Ball, C. Cicchini, C. Battistelli, R. W. Ogrodowicz, E. Christodoulou, S. R. Martin, A. Castello, M. Tripodi, I. A. Taylor, A. Ramos, Nature Commun. 2018, 9, 831, doi: 10.1038/s41467-01803182-3.

[43] D. Koppers-Lalic, M. Hackenberg, I. V. Bijnsdorp, M. A. J. van Eijndhoven, P. Sadek, D. Sie, N. Zini, J. M. Middeldorp, B. Ylstra, R. X. de Menezes, T. Würdinger, G. A. Meijer, D. M. Pegtel, Cell Rep. 2014, 8, 1649, doi: 10.1016/j.celrep.2014.08.027.

[44] A. Iavello, V. S. L. Frech, C. Gai, M. C. Deregibus, P. J. Quesenberry, G. Camussi, Int. J. Mol. Med. 2016, 37, 958, doi: 10.3892/ijmm.2016.2488.

[45] A. R. Soares, T. Martins-Marques, T. Ribeiro-Rodrigues, J. V. Ferreira, S. Catarino, M. J. Pinho, M. Zuzarte, S. Isabel Anjo, B. Manadas, J. P G Sluijter, P. Pereira, H. Girao, Sci. Rep. 2015, 5, 13243, doi: 10.1038/srep13243

[46] T. Thomou, M. A. Mori, J. M. Dreyfuss, M. Konishi, M. Sakaguchi, C. Wolfrum, T. N. Rao, J. N. Winnay, R. Garcia-Martin, S. K. Grinspoon, P. Gorden, C. R. Kahn, Nature 2017, 542, 450, doi: 10.1038/nature21365. 
[47] X. Ren, X. Chen, Z. Wang, D. Wang, J. Reprod. Dev. 2017, 63, 439, doi: 10.1262/jrd.2016-093.

[48] B. Nixon, G. N. De Iuliis, H. M. Hart, W. Zhou, A. Mathe, I. Bernstein, A. L. Anderson, S. J. Stanger, D. A. Skerrett-Byrne, M. F. B. Jamaluddin, J. G. Almazi, E. G. Bromfield, M. R. Larsen, M. D. Dun, Mol. Cell Proteomics 2018, doi: 10.1074/mcp.RA118.000946.

[49] G. Aumüller, H. Renneberg, P. J. Schiemann, B. Wilhelm, J. Seitz, L. Konrad, G. Wennemuth, Adv. Exp. Med. Biol. 1997, 424, 193.

[50] R. Sullivan, Asian J. Androl. 2015, 17, 726, doi: 10.4103/1008-682X.155255.

[51] C. Belleannée, É. Calvo, J. Caballero, R. Sullivan, Biol. Reprod. 2013, 89 30, doi: 10.1095/biolreprod.113.110486.

[52] C. C. Conine, F. Sun, L. Song, J. A. Rivera-Pérez, O. J. Rando, Devel. Cell 2018, 46, 470, doi: 10.1016/j.devcel.2018.06.024.

[53] E. L. Marczylo, A. A. Amoako, J. C. Konje, T. W. Gant, T. H. Marczylo, Epigenetics 2012, 7, 432, doi: 10.4161/epi.19794.

[54] A. B. Rodgers, C. P. Morgan, S. L. Bronson, S. Revello, T. L. Bale, J. Neurosci. 2013, 33, 9003, doi: 10.1523/JNEUROSCI.0914-13.2013.

[55] K. Gapp, A. Jawaid, P. Sarkies, J. Bohacek, P. Pelczar, J. Prados, L. Farinelli, E. Miska, I. M. Mansuy, Nature Neurosci. 2014, 17, 667, doi: 10.1038/ nn.3695.

[56] A. B. Rodgers, C. P. Morgan, N. A. Leu, T. L. Bale, Proc. Natl. Acad. Sci. U.S.A. 2015, 112, 13699, doi: 10.1073/pnas.1508347112.

[57] A. Sharma, J. Theor. Biol. 2014, 357, 143, doi: 10.1016/j.jtbi.2014.05.019.

[58] G. R. Rompala, A. Mounier, C. M. Wolfe, Q. Lin, I. Lefterov, G. E. Homanics, Front. Genet. 2018, 9, 32, doi: 10.3389/fgene.2018.00032.

[59] M. Zuccotti, V. Merico, S. Cecconi, C. A. Redi, S. Garagna, Hum. Reprod. Update 2011, 17, 525, doi: 10.1093/humupd/dmr009.

[60] R. J. Rodgers, H. F. Irving-Rodgers, Biol. Reprod. 2010, 82, 1021, doi: 10.1095/biolreprod.109.082941.

[61] A. Revelli, L. D. Piane, S. Casano, E. Molinari, M. Massobrio, P. Rinaudo, Reprod. Biol. Endocrinol. 2009, 7, 40, doi: 10.1186/1477-7827-7-40.

[62] M. M. H. Sohel, M. Hoelker, S. S. Noferesti, D. Salilew-Wondim, E. Tholen, C. Looft, F. Rings, M. J. Uddin, T. E. Spencer, K. Schellander, D. Tesfaye, PLOS ONE 2013, 8, e78505, doi: 10.1371/journal.pone.0078505.

[63] J. C. da Silveira, D. N. R. Veeramachaneni, Q. A. Winger, E. M. Carnevale, G. J. Bouma, Biol. Reprod. 2012, 86, 71, doi: 10.1095/biolreprod.111.093252.

[64] M. Santonocito, M. Vento, M. R. Guglielmino, R. Battaglia, J. Wahlgren, M. Ragusa, D. Barbagallo, P. Borzì, S. Rizzari, M. Maugeri, P. Scollo, C. Tatone, H. Valadi, M. Purrello, C. Di Pietro, Fertil. Steril. 2014, 102, 1751, doi: 10.1016/j.fertnstert.2014.08.005.
[65] Z. Fereshteh, S. A. Schmidt, A. A. Al-Dossary, M. Accerbi, C. Arighi, J. Cowart, J. L. Song, P. J. Green, K. Choi, S. Yoo, P. A. Martin-DeLeon, Sci. Rep. 2018, 8, 16094, doi: 10.1038/s41598-018-34409-4.

66] E. Delorme-Axford, R. B. Donker, J.-F. Mouillet, T. Chu, A. Bayer, Y. Ouyang, T. Wang, D. B. Stolz, S. N. Sarkar, A. E. Morelli, Y. Sadovsky, C. B. Coyne, PNAS 2013, 110, 12048, doi: 10.1073/pnas.1304718110.

[67] N. K. Kurian, D. Modi, J. Assist. Reprod. Genet. 2018, 36, 189, doi: 10.1007/ s10815-018-1343-X.

[68] J. A. Weber, D. H. Baxter, S. Zhang, D. Y. Huang, K. H. Huang, M. J. Lee, D. J. Galas, K. Wang, Clin. Chem. 2010, 56, 1733, doi: 10.1373/ clinchem.2010.147405.

[69] M. Alsaweed, C. T. Lai, P. E. Hartmann, D. T. Geddes, F. Kakulas, Sci. Rep. 2016, 6, 20680, doi: 10.1038/srep20680.

[70] A. C. Title, R. Denzler, M. Stoffel, J. Biol. Chem. 2015, 290, 23680, doi: 10.1074/jbc.M115.676734.

[71] B. C. Melnik, F. Kakulas, D. T. Geddes, P. E. Hartmann, S. M. John, P. Carrera-Bastos, L. Cordain, G. Schmitz, Nutr. Metab. 2016, 13, 42, doi: 10.1186/s12986-016-0101-2.

[72] P. Rani, M. Vashisht, N. Golla, S. Shandilya, S. K. Onteru, D. Singh, J. Funct. Foods 2017, 34, 431, doi: 10.1016/j.jff.2017.05.009.

[73] T. Wolf, S. R. Baier, J. Zempleni, J. Nutr. 2015, 145, 2201, doi: 10.3945/ jn.115.218586.

[74] S. R. Baier, C. Nguyen, F. Xie, J. R. Wood, J. Zempleni, J. Nutr. 2014, 144, 1495, doi: 10.3945/jn.114.196436.

[75] S. Bruno, C. Grange, M. C. Deregibus, R. A. Calogero, S. Saviozzi, F Collino, L. Morando, A. Busca, M. Falda, B. Bussolati, C. Tetta, G. Camussi, J. Am. Soc. Nephrol. 2009, 20, 1053, doi: 10.1681/ASN.2008070798.

[76] M. Z. Ratajczak, J. Ratajczak, Am. J. Med. Sci. 2017, 354, 449, doi: 10.1016/j.amjms.2017.06.001

[77] T. N. Lamichhane, A. Jeyaram, D. B. Patel, B. Parajuli, N. K. Livingston, N. Arumugasaamy, J. S. Schardt, S. M. Jay, Cell. Mol. Bioeng. 2016, 9, 315, doi: 10.1007/s12195-016-0457-4.

[78] C.-S. Hong, S. Funk, L. Muller, M. Boyiadzis, T. L. Whiteside, J. Extracell. Vesicles 2016, 5, 29289, doi: 10.3402/jev.v5.29289.

[79] T. Yamashita, Y. Takahashi, Y. Takakura, Biol. Pharm. Bull. 2018, 41, 835, doi: 10.1248/bpb.b18-00133.

[80] D. F. Albertini, C. M. Combelles, E. Benecchi, M. J. Carabatsos, Reproduction 2001, 121, 647, doi: 10.1530/rep.0.1210647. 